\title{
Usefulness of the INTERMACS scale for predicting outcomes after urgent heart transplantation
}

\author{
Utilidad de la escala INTERMACS para estratificar el pronóstico tras el \\ trasplante cardiaco urgente
}

Eduardo Barge-Caballero, María J. Paniagua-Martín, Raquel Marzoa-Rivas, Rosa Campo-Pérez, José Ángel Rodríguez-Fernández, Alberto Pérez-Pérez, Lourdes GarcíaBueno, Paula Blanco-Canosa, Zulaika Grille Cancela, Miguel Solla-Buceta, Alberto Juffé-Stein, José M. Herrera-Noreña, José J. Cuenca-Castillo, Javier Muñiz, Alfonso Castro-Beiras, b, María G. Crespo-Leiro

\begin{abstract}
Introduction and objectives. Our aim was to assess the prognostic value of the INTERMACS (Interagency Registry for Mechanically Assisted Circulatory Support) scale in patients undergoing urgent heart transplantation (HT). Methods. Retrospective analysis of 111 patients treated with urgent HT at our institution from April, 1991 to October, 2009. Patients were retrospectively assigned to three levels of the INTERMACS scale according to their clinical status before HT.

Results. Patients at the INTERMACS 1 level $(\mathrm{n}=31)$ more frequently had ischemic heart disease $(\mathrm{p}=0.03)$ and postcardiothomy shock $(\mathrm{p}=0.02)$ than patients at the INTERMACS $2(\mathrm{n}=55)$ and INTERMACS $3-4(\mathrm{n}=25)$ levels. Patients at the INTERMACS 1 level showed higher preoperative catecolamin doses $(p=0.001)$, a higher frequency of use of mechanical ventilation $(p<0.001)$, intraaortic balloon $(p=0.002)$ and ventricular assist devices $(p=0.002)$, and a higher frequency of preoperative infection $(\mathrm{p}=0.015)$. The INTERMACS 1 group also presented higher central venous pressure $(\mathrm{p}=0.02)$, AST $(\mathrm{p}=0.002)$, ALT $(\mathrm{p}=0.006)$ and serum creatinine $(\mathrm{p}<0.001)$, and lower hemoglobin $(p=0.008)$ and creatinine clearance $(p=0.001)$. After HT, patients at the INTERMACS 1 level had a higher incidence of primary graft failure $(p=0.03)$ and postoperative need for renal replacement therapy $(p=0.004)$, and their long-term survival was lower than patients at the INTERMACS $2(\log$ rank 5.1, p = 0.023; HR 3.1, IC 95\% 1.1-8.8) and INTERMACS 3-4 level (log rank 6.1, $\mathrm{p}=0.013$; HR 6.8, IC 95\% 1.2-39.1).

Conclusions. Our results suggest that the INTERMACS scale may be a useful tool to stratify postoperative prognosis after urgent HT.

\section{Resumen}

Introducción y objetivos. Analizar el valor pronóstico de la escala INTERMACS (Interagency Registry for Mechanically Assisted Circulatory Support) en pacientes tratados con trasplante cardiaco urgente.

Métodos. Análisis retrospectivo de 111 pacientes tratados con trasplante cardiaco urgente en nuestro centro entre abril de 1991 y octubre de 2009. Se asignó retrospectivamente a los pacientes a tres niveles de la escala INTERMACS en función de su situación clínica previa al trasplante cardiaco.

Resultados. Los pacientes del grupo INTERMACS $1(\mathrm{n}=31)$ presentaban mayor frecuencia de cardiopatía isquémica $(\mathrm{p}=0,03)$ y shock tras cardiotomía $(\mathrm{p}=0,02)$ que los pacientes del grupo INTERMACS $2(\mathrm{n}=55)$ y los pacientes del grupo INTERMACS 3-4 $(\mathrm{n}=25)$, así como mayores dosis de catecolaminas $(\mathrm{p}=0,001)$, mayor empleo de ventilación mecánica $(\mathrm{p}<0,001)$, balón de contrapulsación $(\mathrm{p}=0,002)$ y dispositivos de asistencia ventricular $(\mathrm{p}=0,002)$ y mayores tasas de infección preoperatoria $(\mathrm{p}=0,015)$. El grupo INTERMACS 1 también mostraba mayores cifras de presión venosa central $(p=0,02)$, GOT $(p=0,002)$, GPT $(p=0,006)$ y creatinina $(p<0,001)$ y menores cifras de hemoglobina $(\mathrm{p}=0,008)$ y aclaramiento de creatinina $(\mathrm{p}=0,001)$. Tras el trasplante cardiaco, los pacientes del grupo INTERMACS 1 presentaron mayores incidencias de fracaso primario del injerto $(p=0,03) \mathrm{y}$ necesidad de terapia de sustitución renal $(\mathrm{p}=0,004)$, y su supervivencia a largo plazo fue menor que la de los pacientes de los grupos INTERMACS 2 ( $\log \operatorname{rank}=5,1 ; \mathrm{p}=0,023$; razón de riesgos $[\mathrm{HR}]=3,1$; intervalo de confianza [IC] del 95\%, 1,4-6,8) e INTERMACS 3-4 (log rank =6,1; $\mathrm{p}=0,013 ; \mathrm{HR}=4$; IC del 95\%, 1,3-12,3).

Conclusiones. Nuestros resultados indican que la escala INTERMACS resulta útil para estratificar el pronóstico postoperatorio tras el trasplante cardiaco urgente.
\end{abstract}


Abbreviations. HF, heart failure; INTERMACS, Interagency Registry for Mechanically Assisted Circulatory Support; HT, heart transplantation; NTO, National Transplant Organization

Keywords. INTERMACS; Heart transplantation; Heart failure; Prognosis

Palabras clave. INTERMACS; Trasplante cardiaco; Insuficiencia cardiaca; Pronóstico

\section{Introduction}

Heart transplantation (HT) improves survival and patient quality of life in select cases of advanced heart diseases that have no possibility of responding to other treatments. ${ }^{1}$ Given that the prognosis for candidates for this type of treatment can be poor due to the time spent waiting for the organ, the National Transplant Organization (NTO) reserves the possibility of granting urgent priority status on the HT waiting list for those patients with a high predicted short-term mortality in the absence of HT.

In Spain, the growing shortage in recent years of optimum donors has led to a progressive increase in HT performed as an urgent procedure, in spite of a postoperative mortality rate that is significantly higher than in elective HT. ${ }^{2}$ The current NTO criteria for including patients on the waiting list for urgent HT establishes a series of levels of priority based solely on the need for various types of life support. ${ }^{3}$ This means that there is a very heterogeneous mix of patients in each priority level with regard to clinical situation, hemodynamic deterioration, and extent of target organ damage. Under these conditions, the current classification does not constitute an optimal tool for making treatment decisions, comparing results between levels or predicting survival following HT.

The INTERMACS (Interagency Registry for Mechanically Assisted Circulatory Support) scale helps to assign patients with advanced heart failure (HF) into seven levels according to hemodynamic profile and level of target organ damage (Table 1). ${ }^{4}$ This classification was defined in the context of a multicenter registry of ventricular assist devices ${ }^{4 \text { and } 5}$ with the objective of unifying criteria to describe the clinical state of advanced HF patients, optimizing perioperative risk prediction and clarifying the instructions for each of the available alternative treatments. The INTERMACS scale has demonstrated its significance in predicting mortality ${ }^{4}{ }^{5}$ and postoperative complications ${ }^{6}$ following the implantation of ventricular assist devices, but as of yet its prognostic value in the context of HT has not been established. The objective of this study is to analyze the usefulness of the INTERMACS scale for stratifying postoperative prognoses in patients with advanced HF receiving urgent HT.

Table 1. INTERMACS (Interagency Registry for Mechanically Assisted Circulatory Support) Scale for Classifying Patients With Advanced Heart Failure.

\begin{tabular}{|c|c|c|}
\hline Profiles & Definition & Description \\
\hline INTERMACS 1 & "Crash and burn" & $\begin{array}{l}\text { Hemodynamic instability in spite of increasing doses of catecholamines and/or } \\
\text { mechanical circulatory support with critical hypoperfusion of target organs (severe } \\
\text { cardiogenic shock) }\end{array}$ \\
\hline INTERMACS 2 & $\begin{array}{l}\text { "Sliding on } \\
\text { inotropes" }\end{array}$ & $\begin{array}{l}\text { Intravenous inotropic support with acceptable blood pressure but rapid deterioration } \\
\text { of kidney function, nutritional state, or signs of congestion }\end{array}$ \\
\hline INTERMACS 3 & "Dependent stability" & $\begin{array}{l}\text { Hemodynamic stability with low or intermediate, but necessary due to hypotension, } \\
\text { doses of inotropics, worsening of symptoms, or progressive kidney failure }\end{array}$ \\
\hline INTERMACS 4 & "Frequent flyer" & $\begin{array}{l}\text { Temporary cessation of inotropic treatment is possible, but the patient presents } \\
\text { frequent symptom recurrences and typically with fluid overload }\end{array}$ \\
\hline INTERMACS 5 & "Housebound" & $\begin{array}{l}\text { Complete cessation of physical activity, stable at rest, but frequently with moderate } \\
\text { water retention and some level of kidney dysfunction }\end{array}$ \\
\hline INTERMACS 6 & "Walking wounded" & $\begin{array}{l}\text { Minor limitation on physical activity and absence of congestion while at rest. Easily } \\
\text { fatigued by light activity }\end{array}$ \\
\hline INTERMACS 7 & "Placeholder" & $\begin{array}{l}\text { Patient in NYHA functional class II or III with no current or recent unstable water } \\
\text { balance }\end{array}$ \\
\hline
\end{tabular}




\section{Methods}

\section{Study Population}

We performed a retrospective analysis of the historical cohort of adult patients treated by an urgent HT at our hospital between April 1991 and October 2009. We included all patients in which urgent HT was indicated due to heart disease with advanced HF and hemodynamic instability and who were dependent on vasoactive amines and/or mechanical circulatory support devices or presented malignant ventricular arrhythmias which were recurrent and refractory to conventional treatment. In all cases a multidisciplinary team of cardiologists, cardiac surgeons and intensivists decided whether to include a patient on the waiting list for urgent HT according to the criteria established by the NTO for each period during the study.

Our protocol until 2001 recommended induction immunosuppressive treatment with OKT-3 antibodies during the first 7 days following HT. Since that time, our team has used induction therapy with basiliximab at days 0 and 4 post-HT. Except for cases with contraindications, all patients received triple immunosuppressive therapy with prednisone, a cell proliferation inhibitor (mycophenolate mofetil or azathioprine) and an anticalcineurinic drug (tacrolimus or cyclosporine) or an mTOR (mammalian target of rapamycin) inhibitor (everolimus or sirolimus).

\section{Data Collection}

The information for the study was obtained by performing individualized reviews of patient medical histories. Patients were informed as to the intent of the study, and each provided their verbal consent in front of witnesses to participate in the analysis of their clinical information. We designed a data collection form which included epidemiological, clinical, treatment, and complementary donor/recipient test variables, as well as those relating to the surgical procedure itself. We defined the following adverse events that could occur during the postoperative hospitalization period after an HT:

- Postoperative death: death due to any cause during the postoperative hospitalization period.

- Major bleeding: bleeding that requires a transfusion of 4 or more units of packed red blood cells and/or causes hemodynamic instability requiring inotropic infusion and/or surgical reintervention.

- Surgical reintervention: cardiac surgery for any reason.

- Renal replacement therapy: need for conventional hemodialysis and/or continuous veno-venous hemodiafiltration.

- Primary graft failure: left ventricle or biventricular systolic dysfunction of the heart graft accompanied by hemodynamic instability, requiring mechanical circulatory support and/or infusion of vasoactive drugs.

- Acute right ventricular failure: isolated systolic dysfunction of the right ventricle in the heart graft accompanied by hemodynamic instability, requiring mechanical circulatory support and/or infusion of vasoactive drugs.

- Acute rejection: Grade 2R or greater acute cellular rejection on the International Society for Heart and Lung Transplantation scale, acute cellular rejection grade $<2 \mathrm{R}$ with hemodynamic compromise, empirical treatment for a suspected acute cellular rejection unproven by biopsy, or a humoral rejection defined as graft dysfunction unexplained by other causes associated with the detection of C4d deposits with a pericapillary pattern in the endomyocardial biopsy using immunofluorescence.

- Infection: any infection as demonstrated using cultures and/or the need for empirical antibiotic treatment due to the suspicion of an infection. For patients that presented infections during hospitalization before the urgent $\mathrm{HT}$, this event was considered only when new infectious agents were isolated in microbiological studies or the antibiotic regimen administered was changed due to suspicion of a new infection.

The information from long-term follow-ups was obtained from the prospective registry at the Heart Transplantation Unit at our center. The authors had reliable data on the vital status of all patients on 19 November 2009. 


\section{INTERMACS Profiles}

The INTERMACS level for each patient immediately before urgent HT surgery was assigned retrospectively and independently by two cardiologists (EBC, MCL) after a detailed revision of their clinical histories. Any discrepancies in the criteria at the time were resolved by consensus. Based on the reduced number of patients assigned to profiles 3 and 4 and because they are frequently alternated in clinical practice, these were combined into one level for analysis. No patients were assigned to levels 5 , 6 , or 7 .

\section{Statistical Analysis}

Categorical variables were presented as absolute frequencies (percentages) and continuous variables were presented as standard deviation of the mean (SD). We used the $\chi 2$ test for comparing categorical variables and an analysis of variance (ANOVA) test for continuous variables. The Scheffé test was used for a posteriori comparison between pairs in the cases where variables showed a statistically significant difference in the ANOVA results. Survival curves were constructed using the Kaplan-Meier method, and compared using a log rank test. Lastly, we constructed a multivariate Cox proportional hazards model with forced inclusion of variables independently associated with survival following HT in our sample (year of HT, diabetes mellitus, age of recipient, sex of recipient) and other variables that, based on existing literature, clinical experience, and/or asymmetrical distribution between the levels, were considered to be potential confounding factors (type of heart disease, previous heart surgery, duration of ischemia, donor age, donor sex, vasoactive support of the donor). All analyses were performed using SPSS version 13.0. The significance level was set at $P<.05$.

\section{Results}

\section{Study Population}

Between April 1999 and October 2009, 112 patients received an urgent HT in our hospital. All complied with the inclusion criteria for the study, except for one patient in which the suggestion for an urgent HT had been motivated by an aortic pathology that was not susceptible to surgical repair. This patient was excluded. Therefore, the study population consisted of 111 patients (18 women) with a mean age of $50.2 \pm 12.9$ years. The INTERMACS level 1 group included 31 patients $(27.9 \%)$, with a mean age of $50.9 \pm 10.3$ years and 3 women $(9.7 \%)$. The INTERMACS level 2 group included 55 patients $(49.6 \%)$ with a mean age of $51.1 \pm 12.6$ years and 8 women $(14.5 \%)$. Lastly, the INTERMACS level 3-4 group consisted of 25 patients $(22.5 \%)$ with a mean age of $48.9 \pm 16.2$ years and 7 women $(28 \%)$.

\section{Preoperative Clinical Characteristics}

Table 2 shows the preoperative clinical characteristics of the study patients. The patients in INTERMACS level 1 had a greater frequency of ischemic heart disease $(P=.03)$ and postcardiotomy shock $(P=.02)$ than patients in levels 2 and 3-4, but the proportion of patients with a New York Heart Association (NYHA) functional class of III-IV before hospitalization which was the principal reason for the urgent HT was significantly higher in the INTERMACS 3-4 group $(P<.001)$. Patients in INTERMACS level 1 required larger doses of vasoactive amines and more frequently received support in the form of mechanical ventilation, balloon counterpulsation, or ventricular assist devices. As a result, the prevalence of preoperative infection was greater in the INTERMACS level 1 group. 
Table 2. Basal Clinical Characteristics of the Study Patients Before the Urgent Heart Transplant Surgery.

\begin{tabular}{|c|c|c|c|c|}
\hline & $\begin{array}{l}\text { INTERMACS } 1 \\
(\mathrm{n}=31)\end{array}$ & $\begin{array}{l}\text { INTERMACS } 2 \\
(\mathrm{n}=55)\end{array}$ & $\begin{array}{l}\text { INTERMACS } 3-4 \\
(\mathrm{n}=25)\end{array}$ & $P$ \\
\hline$B M I(\mathrm{~kg} / \mathrm{m} 2)$ & $25.2(3.0)$ & $25.5(4.6)$ & $25.1(3.5)$ & .91 \\
\hline Female & $3(9.7 \%)$ & $8(14.5 \%)$ & $7(28.0 \%)$ & .16 \\
\hline Basal NYHA class III-IV a & $9(29.0 \%)$ & $32(58.2 \%)$ & $22(88.0 \%)$ & $<.001$ \\
\hline Heart Disease & & & & .03 \\
\hline Ischemic heart disease & $21(67.7 \%)$ & $28(50.9 \%)$ & $7(28.0 \%)$ & \\
\hline Dilated myocardiopathy & $6(19.4 \%)$ & $18(32.7 \%)$ & $15(60.0 \%)$ & \\
\hline Other & $4(12.9 \%)$ & $9(16.4 \%)$ & $3(12.0 \%)$ & \\
\hline Post-cardiotomy shock & $5(16.1 \%)$ & $2(3.6 \%)$ & $0(0.0 \%)$ & .02 \\
\hline Previous heart surgery & $7(22.6 \%)$ & $17(30.9 \%)$ & $6(24.0 \%)$ & .65 \\
\hline Auricular fibrillation & $7(22.6 \%)$ & $18(32.7 \%)$ & $11(44.0 \%)$ & .23 \\
\hline Ventricular arrhythmia & $15(48.4 \%)$ & $17(30.9 \%)$ & $13(52.0 \%)$ & .12 \\
\hline Cardiopulmonary arrest $b$ & $10(32.3 \%)$ & $13(23.6 \%)$ & $10(40.0 \%)$ & .31 \\
\hline Preoperative infection c & $16(51.6 \%)$ & $20(36.4 \%)$ & $5(20.0 \%)$ & .015 \\
\hline$I C D$ & $3(9.7 \%)$ & $8(14.5 \%)$ & $4(12.0 \%)$ & .80 \\
\hline$C R T$ & $1(3.2 \%)$ & $3(5.5 \%)$ & $2(8.0 \%)$ & .73 \\
\hline Anticoagulation treatment & $18(58.2 \%)$ & $39(70.9 \%)$ & $16(64.0 \%)$ & .47 \\
\hline Heparin & $14(45.2 \%)$ & $34(61.8 \%)$ & $10(40.0 \%)$ & \\
\hline Oral anticoagulants & $4(13.0 \%)$ & $5(9.1 \%)$ & $6(24.0 \%)$ & \\
\hline Antiaggregation & $14(45.2 \%)$ & $25(44.4 \%)$ & $6(24.0 \%)$ & .32 \\
\hline Aspirin & $11(35.5 \%)$ & $25(37.1 \%)$ & $6(24.0 \%)$ & \\
\hline Invasive mechanical ventilation & $26(83.9 \%)$ & $28(50.9 \%)$ & $6(24.0 \%)$ & $<.001$ \\
\hline Renal replacement therapy ${ }^{\mathrm{e}}$ & $3(9.7 \%)$ & $1(1.9 \%)$ & $0(0.0 \%)$ & .09 \\
\hline
\end{tabular}

BMI, body mass index; CRT, cardiac resynchronization therapy; ICD, Implantable cardioverter defibrillator; NYHA, New York Heart Association; SD, standard deviation.

Data express mean (standard deviation or $\mathrm{n}(\%)$ ).

${ }^{a}$ Functional class of the patient one month before the hospitalization event that brought about the inclusion on the urgent heart transplant list.

${ }^{\mathrm{b}}$ Episode of ventricular fibrillation, ventricular tachycardia with no pulse, asystole, or electromechanical dissociation.

${ }^{\mathrm{c}}$ Clinical suspicion of infection and isolation of the causative microbe or need for empirical antibiotic treatment before surgery and during the hospitalization period that coincided with the inclusion on the waiting list for an urgent heart transplant.

${ }^{\mathrm{d}}$ Wernovsky inotropic index: dobutamine dose + dopamine dose + adrenaline dose $\times 100+$ noradrenaline dose $\times 100+$ milrinone dose $\times 15 \mu \mathrm{g} / \mathrm{kg} / \mathrm{min}$. Adapted from Wernovsky et al. A comparison of low-flow cardiopulmonary bypass and circulatory arrest. Circulation. 1995;92:2226-35.

${ }^{\mathrm{e}}$ Conventional hemodialysis or continuous veno-venous hemodiafiltration.

\section{Preoperative Hemodynamic Status}

Preoperative hemodynamic parameters are summarized in Table 3. The three INTERMACS levels differed only in central venous pressure $(P=.02)$, which was significantly higher in level 1 patients $(17.8 \pm 3.1 \mathrm{~mm} \mathrm{Hg})$ than in level 2 patients $(10.4 \pm 5.5 \mathrm{~mm} \mathrm{Hg} ; \mathrm{p}=.03)$ and level $3-4$ patients $(9.8 \pm 6.3 \mathrm{~mm} \mathrm{Hg} ; \mathrm{p}=.04)$. 
Table 3. Hemodynamic Situation of Study Patients Before the Urgent Heart Transplantation.

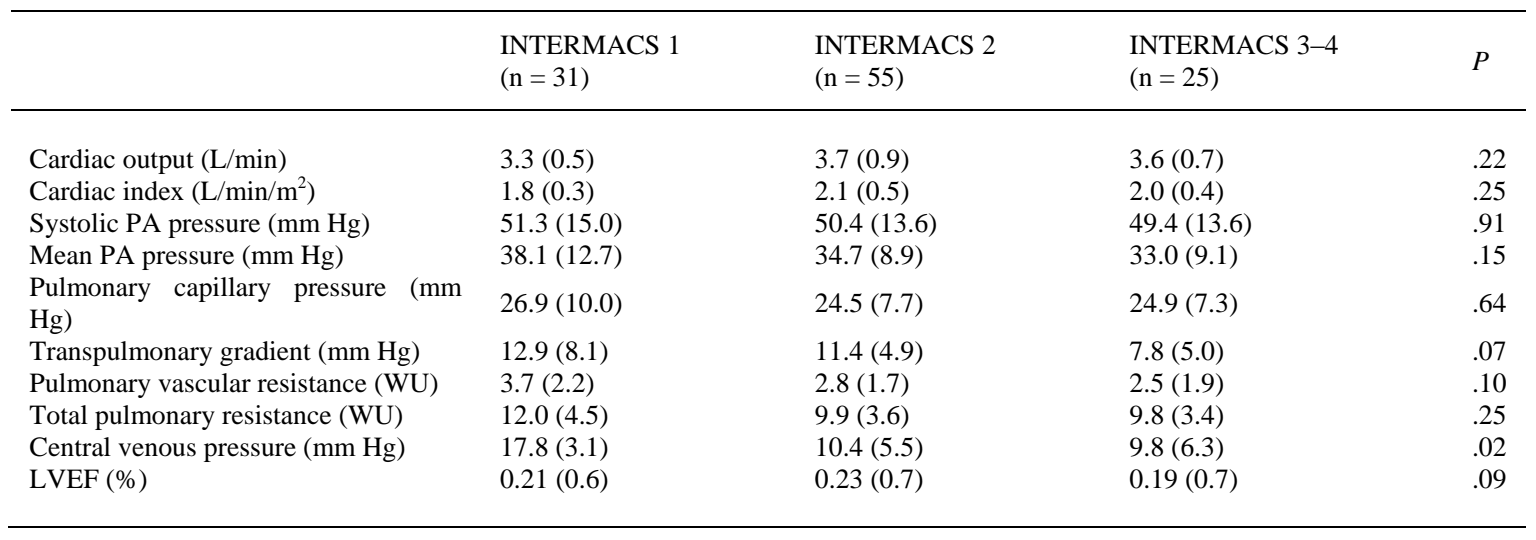

PA, pulmonary artery; WU, Wood units; LVEF, left ventricular ejection fraction.

Data express mean (standard deviation).

\section{Preoperative Laboratory Parameters}

The INTERMACS level 3-4 patients presented significantly higher hemoglobin and hematocrit levels than patients in levels 1 and 2 (Table 4). INTERMACS level 1 patients presented significantly higher levels of glutamate-oxalate transaminase, glutamate-pyruvate transaminase, and lactate dehydrogenase, as well as higher plasma creatinine levels and a lower creatinine clearance than in patients from INTERMACS levels 2 and 3-4.

Table 4. Laboratory Results for Study Patients Before the Urgent Heart Transplantation.

\begin{tabular}{|c|c|c|c|c|}
\hline & INTERMACS $1(\mathrm{n}=31)$ & INTERMACS $2(n=55)$ & INTERMACS 3-4 $(\mathrm{n}=25)$ & $P$ \\
\hline Hemoglobin (g/dL) & $10.8(2.4)$ & $11.3(2.3)$ & $12.7(1.7)$ & .008 \\
\hline Hematocrit $(\%)$ & $31.6(6.9)$ & $34.1(6.8)$ & $37.9(5.1)$ & .004 \\
\hline Total bilirubin (mg/dL) & $2.2(2.1)$ & $1.8(1.7)$ & $2.4(1.7)$ & .45 \\
\hline GOT (UI / L) & $1337(1993)$ & $317(1011)$ & $165(297)$ & .002 \\
\hline GPT (UI / L) & $1220(2403)$ & $205(403)$ & $238(558)$ & .006 \\
\hline GGT (UI / L) & $238(487)$ & $141(172)$ & $93(66)$ & .20 \\
\hline $\mathrm{LDH}(\mathrm{UI} / \mathrm{L})$ & $2494(1968)$ & $1209(1822)$ & $806(550)$ & .002 \\
\hline Creatinine $(\mathrm{mg} / \mathrm{dL})$ & $2.3(1.2)$ & $1.4(0.5)$ & $1.3(0.5)$ & $<.001$ \\
\hline Creatinine clearance $\left(\mathrm{mL} / \mathrm{min} / \mathrm{m}^{2}\right)^{*}$ & $49.1(25.4)$ & $74.3(31.8)$ & $77.7(37.2)$ & 0.001 \\
\hline
\end{tabular}

GGT, gamma-glutamil transpeptidase; GOT, glutamate-oxalacetate transpeptidase; GPT, glutamate-pyruvate transpeptidase; LDH, lactate dehydrogenase; SD, standard deviation.

Data express mean (standard deviation).

* Calculated with the Cockoft-Gault formula: [(140-age) $\times$ weight $($ in $\mathrm{Kg}) /(72 \mathrm{x}$ plasma creatinine $)(\mathrm{mg} / \mathrm{dL})] \times 0.85($ in women $)$.

\section{Heart Transplant}

As displayed in Table 5, the three study groups did not differ significantly in time on the waiting list for urgent HT, the duration of ischemia, or the sex or age of the donors. However, the use of donors that had required vasoactive amines was higher in INTERMACS level 1 patients $(P=.047)$. The time spent on extracorporeal circulation was slightly higher in INTERMACS level 1 patients, although this difference was not significant $(P=.06)$ 
Table 5. Characteristics of the Urgent Heart Transplant (HT) Surgery in Study Patients.

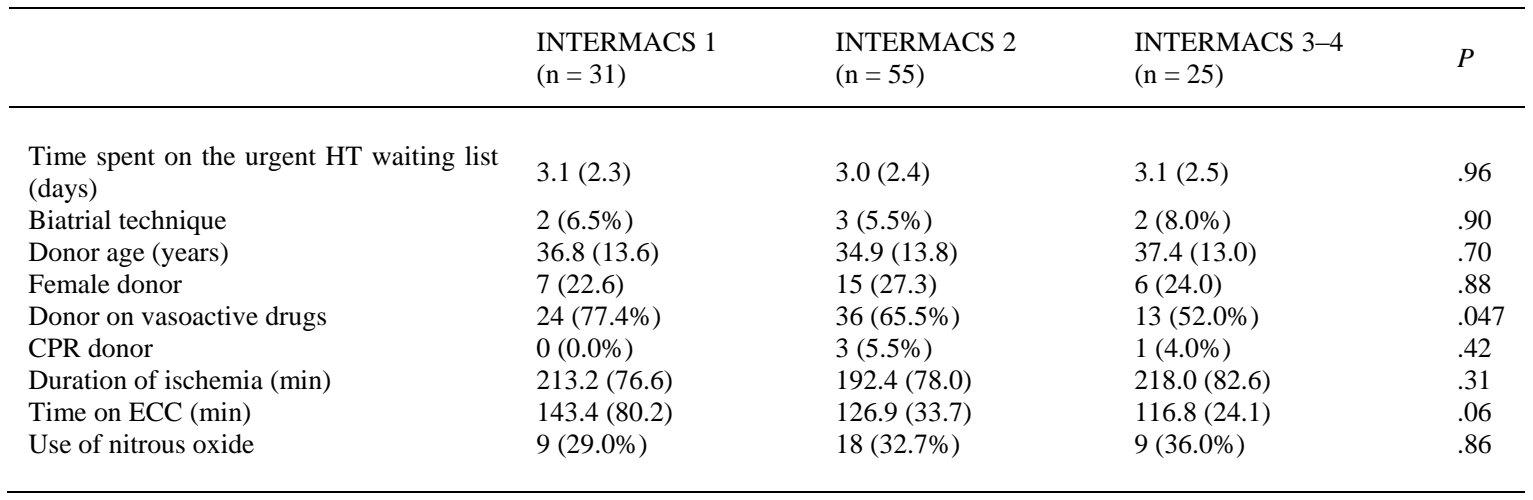

BMI, body mass index; CPR, cardiopulmonary resuscitation; ECC, extracorporeal circulation. Data express mean (standard deviation) or $\mathrm{n}(\%)$.

\section{Postoperative Complications}

The incidence of complications during the postoperative hospitalization period is shown in Figure 1. The incidence of primary graft failures was $35.8 \%$ in INTERMACS level 1 patients, $18.0 \%$ in level 2 , and $12.0 \%$ in level 3-4 $(P=.03)$. Renal replacement therapy was required in $48.4 \%$ of patients in INTERMACS level $1,16.4 \%$ in level 2 , and $20.0 \%$ in level $3(P=.004)$. The incidence of postoperative infections was $51.6 \%$ in INTERMACS level $1,47.3 \%$ in level 2 , and $28.0 \%$ in levels 3 , but this difference was not significant $(P=.09)$. The most frequent postoperative infections were respiratory infections (9 patients in INTERMACS level 1, 12 patients in level 2, and 4 patients in level 3-4), bacteraemia (7 patients in level 1, 5 patients in level 2, and 2 patients in level 3-4), and urinary tract infections (1 patient in level 1 and 3 patients in level 2). During the postoperative period, no statistically significant differences were observed between the three levels in the incidence of isolated right ventricular failure, major bleeding, surgical reoperation, or acute rejection. The intrahospital mortality rate following HT was significantly higher $(P<.001)$ in INTERMACS level 1 patients $(45.2 \%)$ than in level 2 patients $(16.4 \%)$ and level $3-4$ patients $(8.0 \%)$.

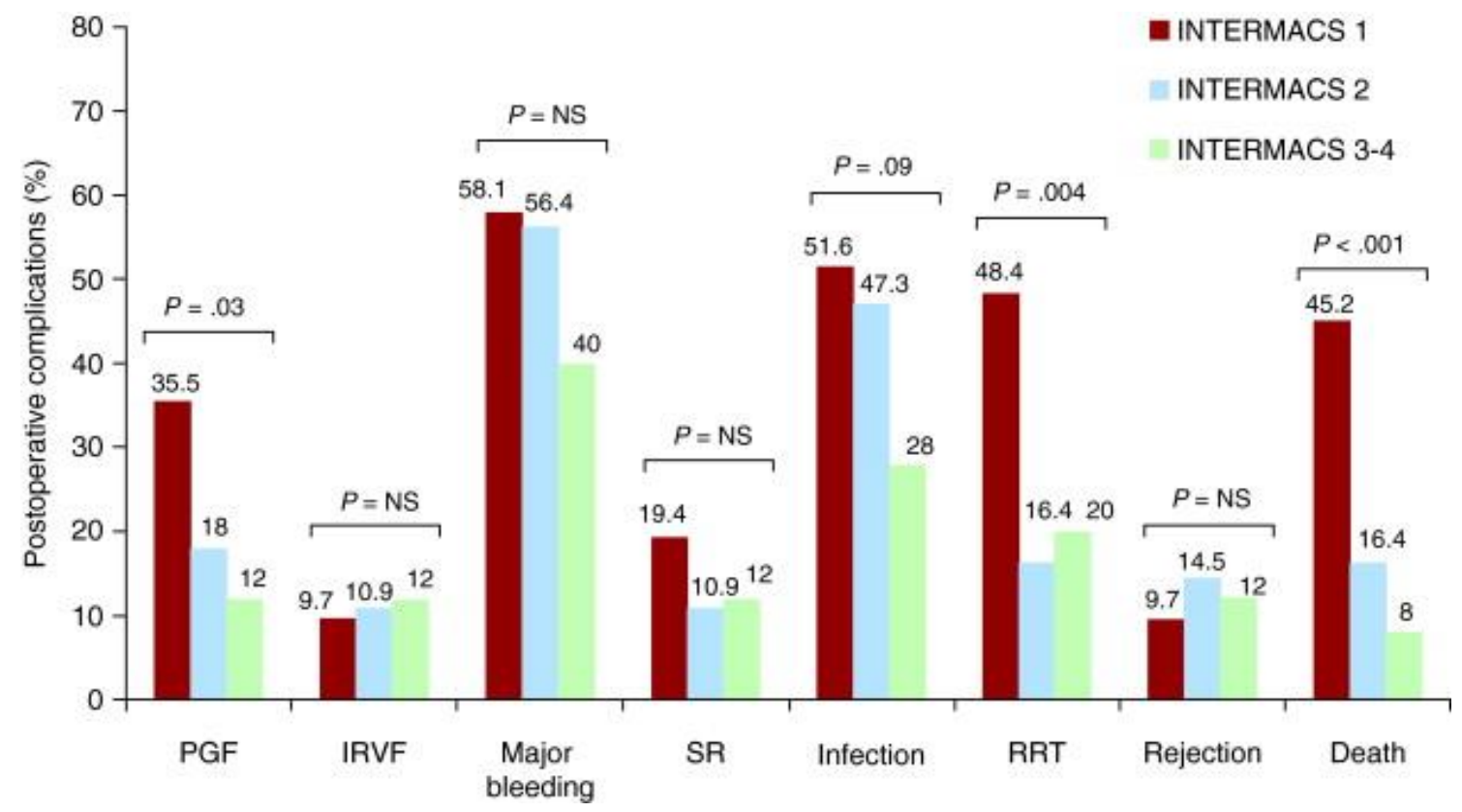

Figure 1. Incidence of postoperative complications in patients included in the study. IRVF, isolated right ventricular failure; PGF, primary graft failure; RRT, renal replacement therapy; SR, surgical reoperation. 
After a mean follow-up of $4.5 \pm 4.3$ years (maximum: 14.9 years), we observed a statistically significant difference between post-HT survival curves for the three study groups $(\log$ rank $8.4, P=.015$; Fig. 2A). The crude and adjusted patient mortality for INTERMACS level 1 patients was significantly higher than in INTERMACS level 2 patients (log rank 5.1, $P=.023$; HR 3.1, 95\% CI 1.4-6.8) and in INTERMACS level 3-4 patients (log rank 6.1, $P=.013$; HR 4.0, 95\% CI 1.3-12.3). We observed no significant differences with regard to crude or adjusted patient mortality between the INTERMACS groups 2 and 3-4 ( $\log$ rank $0.79, P=.37 \mathrm{HR} 1.3,95 \%$ CI $0.4-4.0)$. The greater mortality observed in the INTERMACS level 1 patients was concentrated in the first year post-HT $(\log$ rank 14.3, $P=.01$; Figure $2 \mathrm{~B})$. We observed no significant differences between groups with regard to the long-term prognosis of patients that survived the first year post-transplantation (log rank 0.83, $P=.66$; Fig. 2C). Table 6 outlines the causes of death.
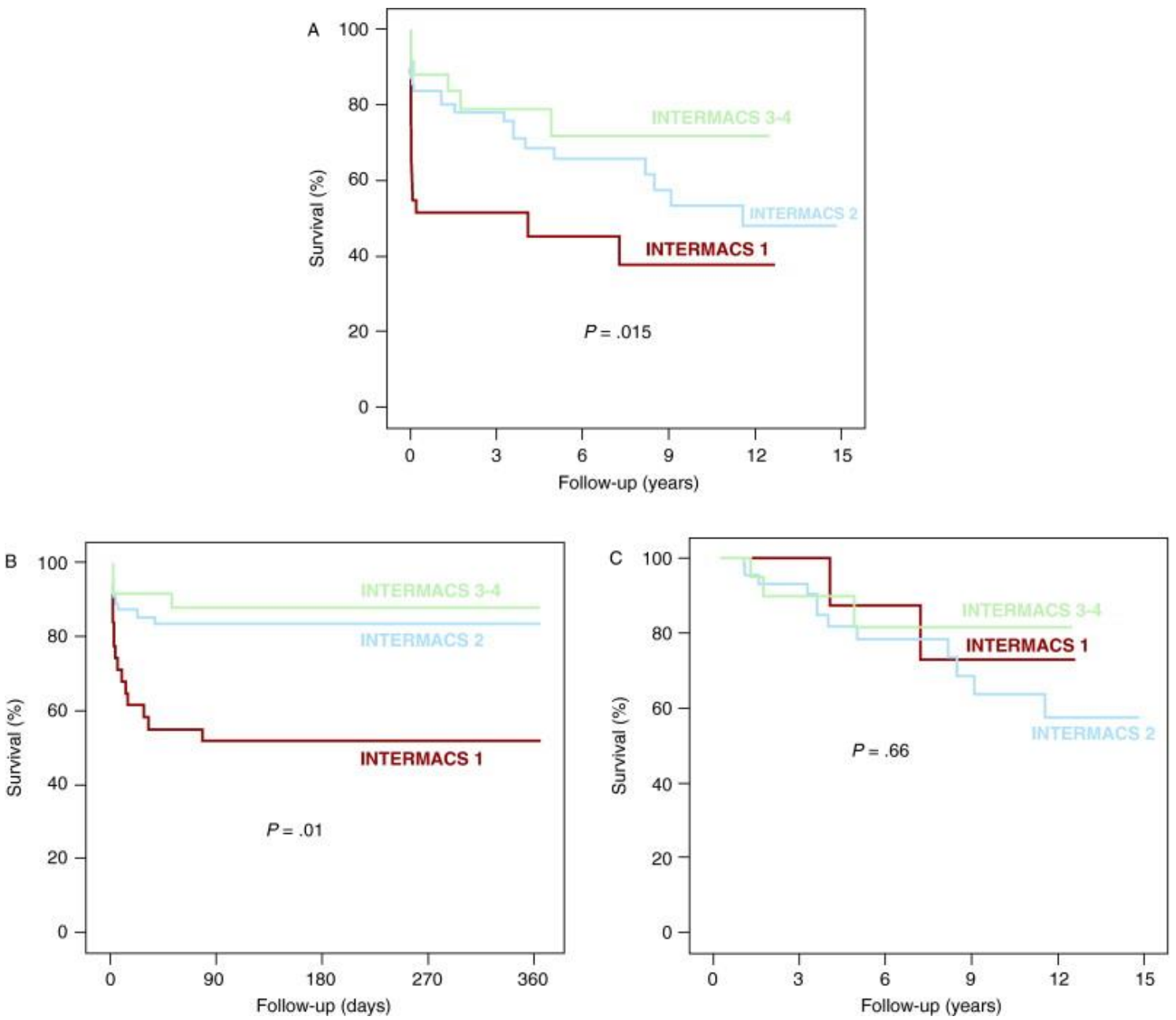

Figure 2. Survival following heart transplantation in patients included in the study. A. Long-term follow-up. B. Follow-up during the first year after the transplant. C. Long-term follow-up of patients that survived the first year after the transplant. 
Table 6. Cause of Death in Study Patients According to INTERMACS Level Before the Urgent Heart Transplant.

\begin{tabular}{lll}
\hline Level & Causes of death $<1$ year postrasplant & Causes of death $>1$ year postrasplant \\
\hline \multirow{2}{*}{ INTERMACS $1(\mathrm{n}=31)$} & $\begin{array}{l}\text { Multi-system failure }(\mathrm{n}=6) \\
\text { Primary graft failure }(\mathrm{n}=5)\end{array}$ & $\begin{array}{l}\text { Acute rejection }(\mathrm{n}=1) \\
\text { Graft coronariopathy }(\mathrm{n}=1)\end{array}$ \\
& Infection $(\mathrm{n}=2)$ & \\
& Other $(\mathrm{n}=2)$ & Neoplasm $(\mathrm{n}=9)$ \\
INTERMACS $2(\mathrm{n}=55)$ & Primary graft failure $(\mathrm{n}=4)$ & $\begin{array}{l}\text { Infection }(\mathrm{n}=2) \\
\text { Graft coronariopathy }(\mathrm{n}=1)\end{array}$ \\
& Multi-system failure $(\mathrm{n}=2)$ & Infection $(\mathrm{n}=1)$ \\
& Othection $(\mathrm{n}=2)$ & Other $(\mathrm{n}=2)$ \\
& Infection $(\mathrm{n}=2)$ & \\
\end{tabular}

\section{Discussion}

The results from our study suggest that the INTERMACS scale is a useful tool for stratifying postoperative prognoses in patients with advanced HF who receive urgent HT. Following an adjustment for potential confounding factors, post-HT mortality of patients that were preoperatively in INTERMACS level 1 (severe cardiogenic shock) was three times greater than in patients in INTERMACS level 2 (rapid clinical deterioration in spite of inotropics) and about four times greater than in patients in INTERMACS level 3-4 (stable NYHA IV with or without inotropics). This result was mainly due to increased mortality as a result of multiorgan failure and primary graft failure during the immediate postoperative period, with no significant differences between groups with respect to long-term survival of patients that survived the first year following HT. Our study showed no significant differences in survival following HT between patients with preoperative placement in INTERMACS level 2 and 3-4.

The main strength that explains the prognostic value of the INTERMACS classification system in patients treated by urgent HT lies in its ability to stratify precisely the clinical and hemodynamic situation of the recipient before the surgical procedure. In this study, the patients that arrived at the HT in INTERMACS level 1 presented a more severe level of hemodynamic deterioration than those in INTERMACS levels 2 and 3-4. They also required preoperative mechanical circulatory support and greater doses of vasoactive amines more frequently. Patients in INTERMACS level 1 also presented more severe dysfunction of target organs. This was reflected in a greater need for invasive ventilatory support and lower analytical parameters of liver and kidney function. In our study, the typical clinical profile of a patient in INTERMACS 1 was that of an individual with ischemic heart disease, good previous functional class or even no previous history of heart failure, presenting an acute coronary event that evolves rapidly into severe cardiogenic shock with severe target organ damage in spite of high doses of vasoactive drugs and mechanical circulatory support. A patient in INTERMACS level 3-4 typically has a known idiopathic dilated myocardiopathy and a history of advanced heart failure, in the majority of cases is already on the elective HT waitlist, presents an episode of decompensation with preservation of target organ function, and requires a lower level of hemodynamic support. The profile of INTERMACS level 2 patients represents an intermediate clinical situation between the two extremes. This scenario is similar to that described in several previous studies using the INTERMACS scale to classify patients with advanced HF that receive a ventricular assist device. 4, 5, 6and 7 An interesting result from our study is the higher frequency of preoperative infection in INTERMACS level 1 patients, which we consider to be related to the higher frequency of using invasive devices. It should be noted that while a controlled infection may not be considered at the time as an absolute contraindication for $\mathrm{HT},{ }^{8}$ this comorbidity could seriously compromise the patient's postoperative evolution in some cases.

The higher early mortality following HT in patients preoperatively in INTERMACS level 1 is mostly due to a high incidence of primary graft failure. This condition, which implies an extremely pessimistic short-term vital prognosis, has classically been considered to be related to donor factors, such as age, need for inotropic support, and duration of ischemia. ${ }^{9}$ In this study, we have observed no significant differences in age, duration of ischemia, or sex of the donors with relation to the preoperative INTERMACS level of the recipient. Furthermore, while the increased frequency of using donors dependent on vasoactive drugs in INTERMACS level 1 patients could have contributed to the high incidence of primary graft failure observed in this group, it does not appear to be the only cause. In recent years, the confirmation of positive HT results from sub-optimal donors in select recipients ${ }^{10}$ has contributed to focusing on the preoperative hemodynamic situation of the recipient as a determining 
factor for the risk of primary graft failure. Similarly, Segovia et $\mathrm{al}^{11}$ have observed a significant association between four dependent variables of the recipient (diabetes mellitus, age $>60$ years, need for inotropic support, and central venous pressure $>10 \mathrm{~mm} \mathrm{Hg}$ ) and the risk of presenting this complication. The last two factors refer to a poor preoperative hemodynamic condition in the recipient, which makes their conclusions congruent with our observation of a high incidence of primary graft failure in patients that arrive at the HT in severe cardiogenic shock. INTERMACS level 1 patients also presented a greater need for renal replacement therapy in the postoperative period, a finding based on the poor preoperative kidney function and evolution of the hemodynamic situation following the surgical procedure.

The confirmation of poor results of urgent HT in patients with an INTERMACS preoperative level 1 status points to the need for reconsidering the clinical management of these cases. Occasionally, a reasonable alternative could be the implantation of a short-term ventricular assist device as a temporary treatment until a definitive decision on the suitability of including the patient on the waiting list for an urgent HT is made. Under these conditions, ventricular assist could facilitate the recuperation of target organ function, which could contribute to optimizing the preoperative condition of the recipient. Although a recent analysis showed a significant increase in postoperative mortality in patients that arrive at their HT with a ventricular assist device, ${ }^{12}$ other groups have obtained positive results using this strategy. ${ }^{13}$ and 14 In spite of the fact that rapid availability of transplant organs has historically led to a reduced use of ventricular assist devices in Spain, ${ }^{15}$ the growing limitations on the number of donors would be expected to constitute a strong impulse for this type of program in coming years. In any case, it is important to remember that decision-making for the treatment of patients in deep cardiogenic shock must ride on a careful assessment of the potential reversibility of damage to target organs: if irreversible, any treatment effort will probably be useless (a situation that some authors have considered INTERMACS level 0). It is possible, in fact, that performing urgent HT in some patients poised on the brink of irreversible multiorgan failure may have led to the high mortality observed in the INTERMACS level 1 group from our study. With an optimal distribution of donors, it would be useful to have clinical markers available that identify the "point of no return" in this high-risk population, for which an HT implies an unacceptable perioperative mortality rate and therefore should be contraindicated. Due to the sample size, this task is beyond the bounds of the goals of our research, but could constitute an interesting field of research for future multicenter studies.

The most important limitation of our study was its retrospective design, which could have led to some errors in the assignment of preoperative INTERMACS levels. For a correct interpretation of the results, one must keep in mind the heterogeneity of the sample and the variation in selection criteria for urgent HT candidates throughout the years comprising the study period. Furthermore, the reduced sample size has not allowed us to single out statistically significant differences between groups that could be clinically relevant, as described in the "Discussion". Lastly, the design of our analysis does not allow us to guarantee the external validity of the conclusions made. These must therefore be confirmed in future multicenter registries with larger sample sizes.

\section{Conclusions}

In spite of the aforementioned limitations, our study suggests that the INTERMACS scale can be useful to stratify the postoperative prognosis of patients with advanced HF that receive urgent HT. In our opinion, the elevated postoperative mortality rate observed in patients that arrive to their urgent HT in severe cardiogenic shock points to the need to rethink the treatment strategy in these cases and to stimulate the development of ventricular assist programs. Even if these results are not confirmed by future multicenter registries, the INTERMACS scale could still be a useful tool to optimize the selection of candidates for urgent HT and the distribution of heart donors in our field, and therefore could be incorporated in the near future into the habitual clinical practice of professionals in this field.

\section{Conflicts of interest}

None declared.

\section{Funding}

This article was partially financed by the Instituto Nacional de Salud Carlos III (Carlos III National Health Institute) through the Red Nacional de Investigación Cardiovascular (RECAVA) (National Network of Cardiovascular Research). 


\section{Acknowledgements}

We would like to thank the entire staff of the Oficina de Coordinación de Trasplantes (Transplant Coordination Office) and the Trasplante Cardiaco (Heart Transplant) program of the Hospital Universitario de A Coruña (Coruña University Hospital) throughout their 19-year history (1991-2010).

\section{Bibliography}

1.Dickstein K, Cohen-Solal A, Filippatos G, McMurray JJ, Ponikowski P, Poole-Wilson PA, et al. ESC Guidelines for the diagnosis and treatment of acute and chronic heart failure 2008: the Task Force for the Diagnosis and Treatment of Acute and Chronic Heart Failure 2008 of the European Society of Cardiology. Developed in collaboration with the Heart Failure Association of the ESC (HFA) and endorsed by the European Society of Intensive Care Medicine (ESICM). Eur Heart J. 2008; 29:2388-442.

2.Almenar Bonet L. Spanish Heart Transplantation Registry. 20th official report of the Spanish Society of Cardiology Working Group on Heart Failure and Heart Transplantation (1984-2008). Rev Esp Cardiol. 2009; 62:1286-96.

3.Criterios de distribución de donantes cardiacos (año 2010). Organización Nacional de Trasplantes. Ministerio de Sanidad y Política Social. http://www.ont.es/infesp/Paginas/CriteriosdeDistribucion.aspx.

4.Stevenson LW, Pagani FD, Young JB, Jessup M, Miller L, Kormos RL, et al. INTERMACS profiles of advanced heart failure: the current picture. J Heart Lung Transplant. 2009; 28:535-41.

5.Holman WL, Pae WE, Teutenberg JJ, Acker MA, Naftel DC, Sun BC, et al. INTERMACS: interval analysis of registry data. J Am Coll Surg. 2009; 208:755-61. discussion 61-2

6.Alba AC, Rao V, Ivanov J, Ross HJ, Delgado D.H. Usefulness of the INTERMACS scale to predict outcomes after mechanical assist device implantation. J Heart Lung Transplant. 2009; 28:827-33.

7.Kirklin JK, Naftel DC, Kormos RL, Stevenson LW, Pagani FD, Miller MA, et al. Second INTERMACS annual report: more than 1,000 primary left ventricular assist device implants. J Heart Lung Transplant. 2010; 29:1-10.

8.Anguita M, Arizon JM, Valles F, Torres F, Lopez-Rubio F, Concha M. Results of heart transplantation in recipients with active infection. J Heart Lung Transplant. 1993; 12:808-9.

9.Huang J, Trinkaus K, Huddleston CB, Mendeloff EN, Spray TL, Canter CE, et al. Risk factors for primary graft failure after pediatric cardiac transplantation: importance of recipient and donor characteristics. J Heart Lung Transplant. 2004; 23:716-22.

10.Lima B, Rajagopal K, Petersen RP, Shah AS, Soule B, Felker GM, et al. Marginal cardiac allografts do not have increased primary graft dysfunction in alternate list transplantation. Circulation. 2006; 114(1 Suppl):I27-32. 11.Segovia J, Barcelo JM, Gomez-Bueno M, Cobo M, Garcia-Pavia P, Mirelis J, et al. A novel primary graft failure risk score in heart transplantation. J Heart Lung Transplant. 2009;28:2S:157 (abstract).

12.Patlolla V, Patten R, DeNofrio D, Konstam M, Krishnamani R. The effect of ventricular assist devices on posttransplant mortality: an analysis of the United Network of Organ Sharing Thoracic Registry. J Am Coll Cardiol. 2009; 53:264-71.

13.Russo MJ, Honk K, Davies R, Chen J, Sorabella R, Ascheim D, et al. Posttransplant survival is not diminished in heart transplant recipients bridged with implantable left ventricular assist devices. J Thorac Cardiovasc Surg. 2009; 138:1425-1432.e1\%\%\%\#x02013;3.

14.Cleveland J, Grover F, Fullerton D, Campbell D, Mitchell M, Lindelfeld J, et al. Left ventricular assist device as bridge to transplantation does not adversely affect one-year heart transplantation survival. J Thorac Cardiovasc Surg. 2008; 136:774-7.

15.Perez de la Sota E. Concepto, historia y métodos de asistencia ventricular. Cir Cardiov. 2008; 15:51-8. 